EXTENDED REPORT

\title{
Engaging families in health services research on childhood visual impairment: barriers to, and degree and nature of bias in, participation
}

\author{
J S Rahi, I Manaras, H Tuomainen, G Lewando Hundt
}

Br J Ophthalmol 2004;88:782-787. doi: 10.1136/bjo.2003.033258

See end of article for authors' affiliations

....................

Correspondence to: J Rahi, Centre for Paediatric Epidemiology and Biostatistics, Institute of Child Health, 30 Guilford Street, London WCIN 1EH, UK; j.rahi@ich.ucl. ac.uk

Accepted for publication 30 November 2003

\begin{abstract}
Aim: To investigate the barriers to, and degree and nature of bias in, participation in health services research by parents of children with visual impairment.

Methods: Parents of children newly diagnosed with ophthalmic disorders at Great Ormond Street Hospital, London, participated in a study to elicit their health service experiences and needs through a postal questionnaire survey followed by in-depth interviews. The participating and non-participating families were compared at different stages of recruitment, according to sociodemographic and clinical characteristics.

Results: $20 \%$ (55) of all eligible families could not be invited to participate because of out of date contact details for either the family and/or family doctor in the hospital and/or community record systems. Completed questionnaires were received from 67\% (147/221) of contacted families, although only 6\% actively declined to take part. Compared to non-participating parents, those who took part were more likely to be white British, from higher socioeconomic groups, have English as their main language, and have no other visually impaired family members. There were no significant differences according to the clinical characteristics of their affected children.

Conclusions: Families from socioeconomically deprived and ethnic minority groups are likely to be less visible than others in health services research on childhood visual impairment. Geographical mobility in families of young children with visual disability poses a potentially important obstacle to engaging them in research on their experiences of health services. These findings indicate the importance of addressing potential biases in the design and interpretation of future studies, to ensure equity in recommendations for policy and practice, and in implementation of services.
\end{abstract}

B roadening and improving the nature and scope of services for children with disability and their families is an international priority. ${ }^{12}$ The importance of engaging users of health care in research informing the planning or provision of services is well established..$^{3-5}$ The case for this is particularly strong in relation to the parents of children with disability, whose role as advocates and mediators for their children is acknowledged within the international disability movement. ${ }^{2}$ However, there has been limited work on the optimum ways of engaging parents of disabled children in such health services research. We report the barriers to, and degree and nature of bias in, participation by parents of children with visual impairment in a study to elicit their health service experiences and needs.

\section{METHODS}

Between 2000 and 2002, we undertook a study of the health service experiences and needs of parents during the 1218 months following new diagnoses of ophthalmic disorders in their children, using a postal questionnaire survey followed by in-depth individual interviews. The findings are to be reported separately. The families of all children newly diagnosed in one of two 12 month periods (August 1999 to July 2000 and December 2000 to November 2001, respectively) in the Department of Ophthalmology, Great Ormond Street Hospital (GOS) were eligible. In August 2000, a new service (GOS Ophthalmology "community link team") was implemented in the department. This comprised two "key workers" who were present during the families' first consultation and subsequently provided information, support, and liaison as necessary. Thus, the two groups of families differed with respect to experience of the community link team.

\section{Identification of eligible children and families}

In the absence of an existing database from which families of eligible children could be identified, we used the GOS hospital patient information system to identify all children attending an outpatient appointment for the first time (new patients) during the two study periods. As most visually disabling disorders in children in the United Kingdom are present from birth or develop in early childhood, ${ }^{6}$ only those children aged 5 years or less were selected from this list. For each child selected we retrieved and examined the ophthalmology department correspondence (electronic and/or paper documents) to ascertain whether he/she had been newly diagnosed during the study ascertainment period, and was thus eligible for inclusion. All available addresses and contact telephone numbers for both parents and the family doctor were extracted for each eligible child.

We wrote to the family doctor of each child, informing him/her of the aims and design of the study, giving the current contact details we held, and asking if they felt there were any reasons the family should not be contacted (for example, death of the affected child or other major family events). A proforma and reply paid envelope were provided, together with contact details of the research team. Nonreplying doctors were contacted by telephone 2 weeks later.

\section{Postal questionnaire survey}

The parents of all children for whom the family doctor had replied, indicating there were no reasons to preclude 
involvement in the study, were sent a study pack. This contained a letter asking them to take part, signed by members of the research team and providing contact details for them. To the consent form was appended a detailed explanation of the purpose and design of the study, together with assurances about the confidential handling of all information provided and that their child's management would not be affected by their decision regarding participation. A copy of each questionnaire was provided for each parent. The main instrument was the Measure of Processes of Care (MPOC) a 56 item English language validated questionnaire which has been developed ${ }^{78}$ and used successfully $y^{9-13}$ to evaluate parental experiences of health services for a range of childhood disorders or impairments. Overall satisfaction with services was elicited using the Client Satisfaction Questionnaire, ${ }^{14}$ which has been employed previously in studies of parental satisfaction with paediatric services, ${ }^{15}$ including in conjunction with the MPOC. ${ }^{7}$ Parents' views and experiences regarding the GOS Ophthalmology community link team were sought using open and closed ended questions. Detailed socioeconomic and demographic information about education, occupation, home and car ownership was also sought by questionnaire. Finally, a form requesting the telephone number(s) at which the parents preferred to be contacted was included, together with a form to decline involvement in the study, and reply paid envelopes for the return of study documents.
Two weeks later non-responding parents were contacted by telephone at home in the early evening. A simple set of questions was used to confirm the study pack had been received and to elicit and address any questions or difficulties in completing the questionnaire, such as whether use of the GOS translator service was required or whether telephone administration by the researcher would be helpful. Where necessary, the researcher fluent in Hindi, made this contact with families of children whose names indicated that they may be of Indian, Pakistani, or Bangladeshi origin, comprising the main ethnic minority groups among visually impaired children in the United Kingdom. Directory inquiries were used to try to ascertain telephone numbers that were unavailable or incorrect in the hospital records. Two weeks later a second full study pack was sent to remaining nonresponding parents. No further contact was made with parents who did not reply.

\section{Examining bias in participation}

The hospital records of all children considered eligible at the outset were retrieved and examined. Using these, and entries in the hospital patient information management system, clinical and sociodemographic information was extracted and recorded on detailed forms. This included the child's age, sex, ethnic group, ophthalmic diagnosis, severity of visual loss, and presence of additional nonophthalmic impairments/disorders, together with family

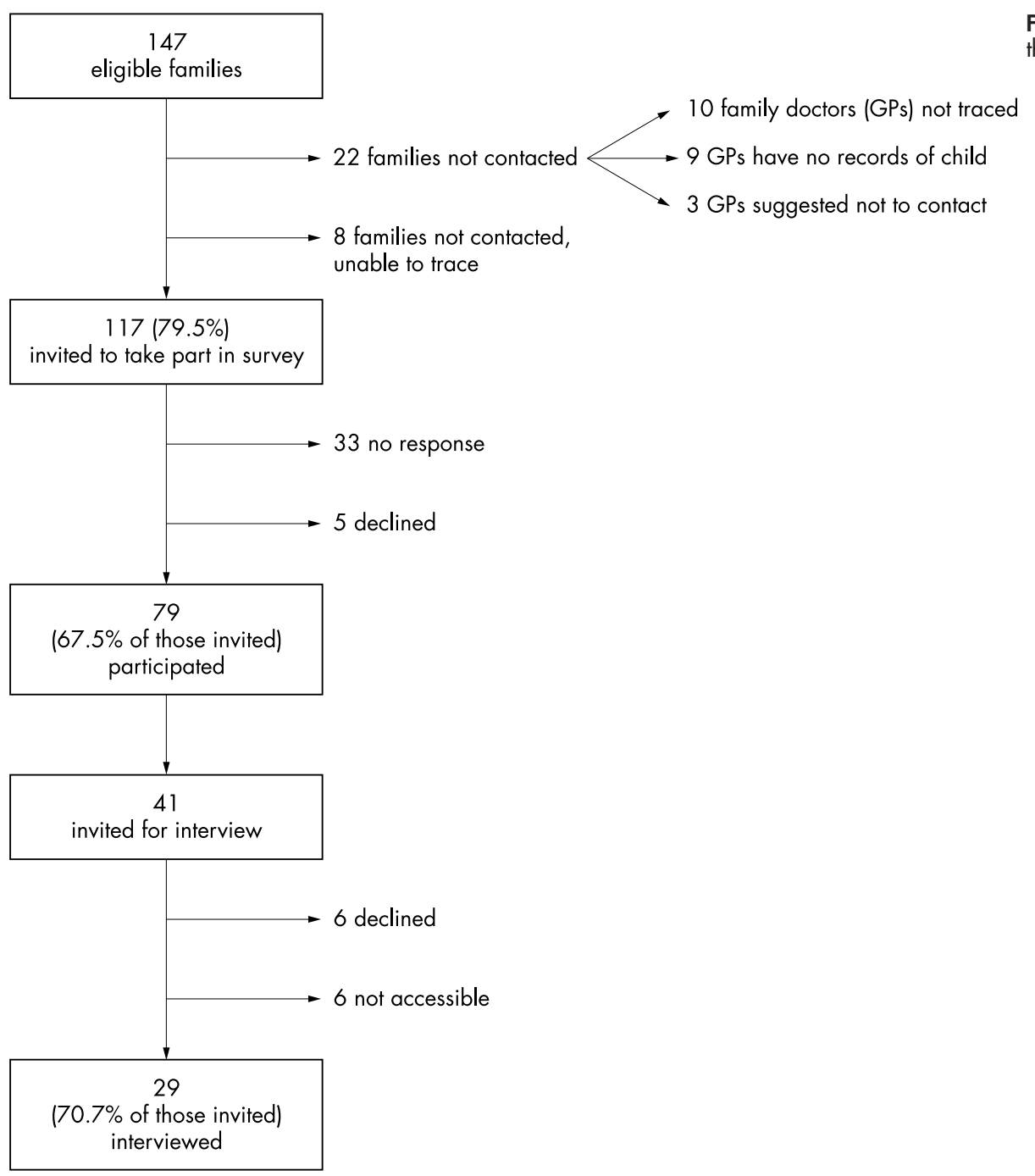

Figure 1 Flow chart of recruitment in the pre-CLT group. 
history of visual impairment, postcode, and parents' main language.

We examined possible participation bias in the questionnaire survey in an ongoing fashion. This enabled a stratified subsample of those returning completed questionnaires to be invited to take part in personal interviews, to ensure adequate representation of ethnic minority or more deprived families, as well as of fathers. Hence we did not examine participation bias at the interview stage.

\section{Statistical analyses}

All data were entered in to a relational database (Access 97, Microsoft Corporation, Washington, USA) and descriptive analyses were undertaken using SPSS 11 (2001, SPSS Inc, Chicago, IL, USA). Level of participation at each stage of the study was assessed. Participating and non-participating parents were compared with respect to sociodemographic factors and clinical characteristics of their children using the test for differences in two proportions ${ }^{16}$ and/or odds ratios (OR) using Epi-Info V 6.0. (CDC, Atlanta, GA, USA) We were interested, a priori, in investigating the role of parents socioeconomic status (using the Townsend deprivation index ${ }^{17}$ based on postal code), main language, as well as the child's ethnic group (according to the UK Office for National Statistics classification ${ }^{18}$ ), the severity of her/his visual loss, and the presence of other non-ophthalmic impairments or chronic disorders, as well as whether there was a family history of visual impairment. As we were uncertain whether experience of the community link team (CLT) would itself impact on participation, we examined the pre-CLT group and the post-CLT groups separately.

The study was approved by the Great Ormond Street Hospital/Institute of Child Health local research ethics committee and conformed to the principles embedded in the Declaration of Helsinki.

\section{RESULTS}

Altogether, the families of 276 children were considered to be eligible. Of these, $20 \%$ (55) could not be invited to participate: the family doctor could not be traced (17), or had no record of the child in his/her practice (20), or advised against contacting the family (nine); or the address for the child in the hospital record system was out of date and no forwarding address could be found (nine).

The levels of participation at each stage of recruitment in the study are shown separately for the pre-CLT and post-CLT groups in figures 1 and 2 respectively. In both groups, there was a higher level of participation in interviews, by those who had already completed questionnaires, than in the questionnaire survey itself.

Participants were compared with non-participants and those not contacted in the pre-CLT group (table 1) and the post-CLT group (table 2). Compared to those who did not take part, participating families in the pre-CLT group were

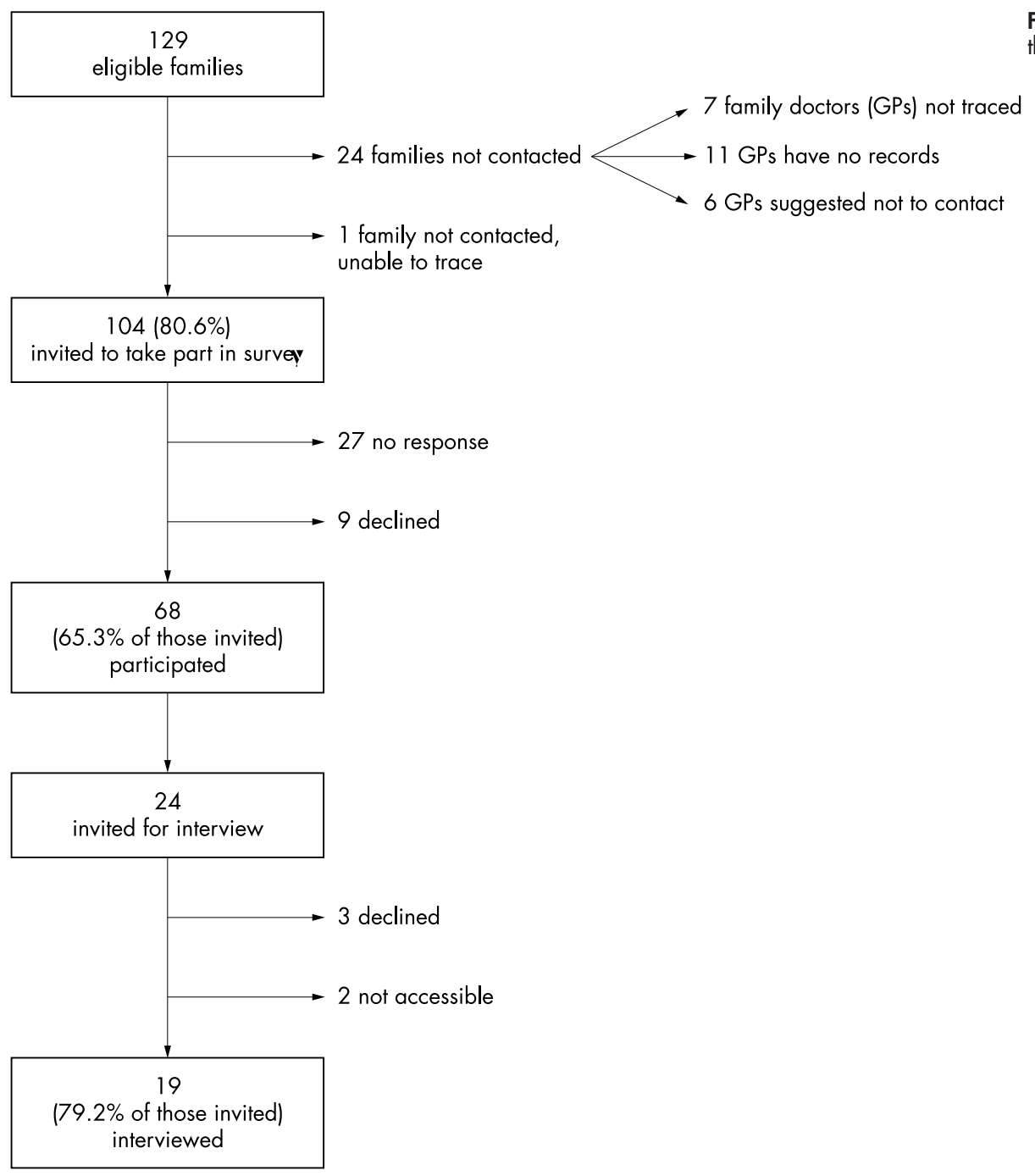

Figure 2 Flow chart of recruitment in the post-CLT group. 
significantly $(p \leqslant 0.05)$ less likely to be socioeconomically deprived and significantly more likely to have English as their main language, have younger children, as well children categorised as in the white ethnic group. ${ }^{18}$ In the post-CLT group, participants were significantly more likely than those who did not take part, to have a family history of visual impairment. They were also significantly more likely than those who could not be contacted, to be from higher socioeconomic groups and have English as their main language.

There were no consistent significant differences in participation according to clinical characteristics including the severity of visual loss, individual ophthalmic disorders, or presence of other non-ophthalmic impairments.

In all, $12.6 \%$ (10) of the pre-CLT and $11.5 \%$ (seven) of the post-CLT groups comprised single parent families. Mothers participated more than fathers-separate questionnaires being completed by mothers for $93.7 \%(74)$ and fathers for $51.8 \%(41)$ of children in the pre-CLT group, for $89.7 \%$ (61) and $57.4 \%(35)$ in the post-CLT groups, respectively. There were insufficient data on non-responders in the hospital records to allow examination of participation by family structure (one versus two parents) or parental occupation or education. Our sample was too small to undertake "wave" analysis $^{19}$ to determine whether those who participated early (without reminders) differed from those who participated after prompting.

\section{DISCUSSION}

The level of parental participation is our study was similar to that reported in other studies using the $\mathrm{MPOC}^{7-11}$ or other questionnaires ${ }^{15} 2021$ to elicit the needs, and satisfaction with services, of parents of children with disability. Participation did not seem to be influenced by the clinical characteristics of the children, but rather by complex sociocultural factors, acting both at the level of the individual and the level of family, which may distinguish families with disabled children from those without. ${ }^{22}$ Thus, participation might be different if families were studied at a later time in the child's life (for example, around school entry, by which time parents' experiences of heath services and their balance of concerns would be expected to be different) or if the setting had not been a specialist unit. The extent of non-participation bias in our study is small. However, the less "visible" children were from socioeconomically deprived and ethnic minority groups, who, despite efforts to reduce inequities, continue to differ from less deprived and white children in their use of healthcare services. ${ }^{23-25}$ Thus we recognise that their needs are also likely to differ, with implications for recommendations about services for visually impaired children based on our study.

There is an extensive literature on the importance of reducing non-response bias in health services research in adults, including about disability. ${ }^{19}$ Appropriate study design together with assessment of level and nature of bias and accounting for this in statistical analyses, wherever possible, are advocated. Non-response in research on children includes the added layer of complexity of parents and families and has been less extensively studied. ${ }^{192}$ Conflicting findings have been reported regarding the influence of both parental factors (age, ethnicity, language, educational level, income, wellbeing, and stress), and family factors (environment, structure, and history of disease) and also about the importance of the nature and severity of the disorder affecting the child. ${ }^{22}$ 26-29 In research that aims to inform policy or service provision, the importance of biased participation is its impact on the generalisability of the findings.

The topic of our study should have been of interest to all parents invited to take part, and although we sought potentially sensitive information using questionnaires that together take about 30 minutes to complete, similar research in other areas suggests that these are unlikely to have been major disincentives. ${ }^{4} 15202130-32$ We adopted all the main strategies that have subsequently been reported to improve

Table 1 Comparison of respondents, non-respondents, and those not contacted in the pre-CLT group

\begin{tabular}{|c|c|c|c|c|c|c|c|}
\hline & $\begin{array}{l}\text { Respondents } \\
(\mathrm{n}=79)\end{array}$ & $\begin{array}{l}\text { Non- } \\
\text { respondents } \\
(\mathrm{n}=38)\end{array}$ & $\begin{array}{l}\text { Difference in proportions } \\
\text { (respondents } \mathrm{v} \text { non- } \\
\text { respondents) }\end{array}$ & & $\begin{array}{l}\text { Not } \\
\text { contacted } \\
(n=30)\end{array}$ & $\begin{array}{l}\text { Difference in } \\
\text { proportions } \\
\text { (respondents v } \\
\text { not-contacted) }\end{array}$ & \\
\hline & $\%(N)$ & $\%(\mathbf{N})$ & $(95 \% \mathrm{Cl})$ & $\mathrm{p}$ Value & $\%(\mathbf{N})$ & $(95 \% \mathrm{Cl})$ & p Value \\
\hline \multicolumn{8}{|l|}{ Severity } \\
\hline Severe & $29(22)$ & $18(7)$ & 11 (6 to 25$)$ & 0.34 & $33(10)$ & $4(-15,19)$ & 0.98 \\
\hline Moderate & $39(30)$ & $41(16)$ & $3(-16$ to 22$)$ & 0.90 & 27 (8) & 12 (1 to 34$)$ & 0.09 \\
\hline Mild & $32(25)$ & $41(16)$ & $9(-9$ to 28$)$ & 0.42 & $40(12)$ & $8(-17$ to 19$)$ & 0.91 \\
\hline \multicolumn{8}{|l|}{ Parent's language } \\
\hline English & $97(75)$ & $61(19)$ & 36 (19 to 54$)$ & 0.00001 & $90(18)$ & $7(-6$ to 21$)$ & 0.40 \\
\hline Other & $3(2)$ & 39 (12) & & & $10(2)$ & & \\
\hline \multicolumn{8}{|c|}{ Visual impairment in the family } \\
\hline Yes & $24(17)$ & $32(11)$ & $8(-11$ to 27$)$ & 0.53 & $46(10)$ & $22(-2$ to 44$)$ & 0.10 \\
\hline No & $76(53)$ & $68(23)$ & & & 54 (12) & & \\
\hline \multicolumn{8}{|l|}{ Complexity of condition } \\
\hline $\begin{array}{l}\text { Visual impairment } \\
\text { alone }\end{array}$ & $49(38)$ & $59(17)$ & $10(-11$ to 30$)$ & 0.53 & $53(16)$ & $4(-17$ to 25$)$ & 0.88 \\
\hline $\begin{array}{l}\text { Additional } \\
\text { systemic problems }\end{array}$ & $51(39)$ & $41(12)$ & & & $47(14)$ & & \\
\hline \multicolumn{8}{|l|}{ Ethnicity* } \\
\hline White & $91(70)$ & $75(29)$ & $16(1$ to 30$)$ & 0.05 & $82(18)$ & $9(8-26)$ & 0.42 \\
\hline Non-white & 9 (7) & $25(9)$ & & & $18(4)$ & & \\
\hline \multicolumn{8}{|c|}{ Deprivation (population quintiles) } \\
\hline 1 st, 2nd, 3rd quintile & $73(32)$ & $44(11)$ & 29 (1 to 47$)$ & 0.08 & $55(6)$ & $18(-18$ to 46$)$ & 0.62 \\
\hline 4th, 5th quintile & 27 (15) & $56(14)$ & & & $45(5)$ & & \\
\hline \multicolumn{8}{|l|}{ Deprivation index } \\
\hline Mean & -0.52 & 1.23 & $t=-2.90$ & 0.005 & 1.58 & $t=-1.80$ & 0.07 \\
\hline \multirow{2}{*}{\multicolumn{8}{|c|}{ Age of child }} \\
\hline & & & & & & & \\
\hline Mean & 2.48 & 3.80 & $t=-3.66$ & 0.00004 & 2.75 & $t=-.71$ & 0.47 \\
\hline SD & 1.78 & 1.96 & & & 1.78 & & \\
\hline
\end{tabular}


Table 2 Comparison of respondents, non-respondents, and those not contacted in the post-CLT group

\begin{tabular}{|c|c|c|c|c|c|c|c|}
\hline & \multirow{2}{*}{$\begin{array}{l}\text { Respondents } \\
\text { ( } n=68) \\
\%(N)\end{array}$} & \multirow{2}{*}{$\begin{array}{l}\text { Non- } \\
\text { respondents } \\
\text { (n=36) } \\
\%(\mathrm{~N})\end{array}$} & \multirow{2}{*}{$\begin{array}{l}\text { Difference in proportions } \\
\text { (respondents } v \text { non- } \\
\text { respondents) } \\
(95 \% \mathrm{Cl})\end{array}$} & \multirow{2}{*}{ p Value } & \multirow{2}{*}{$\begin{array}{l}\text { Not contacted } \\
(n=25) \\
\%(N)\end{array}$} & \multirow{2}{*}{$\begin{array}{l}\text { Difference in } \\
\text { proportions } \\
\text { (respondents v not- } \\
\text { contacted) } \\
(95 \% \mathrm{Cl})\end{array}$} & \multirow[b]{2}{*}{ p Value } \\
\hline & & & & & & & \\
\hline \multicolumn{8}{|l|}{ Severity } \\
\hline Severe & $23(16)$ & $28(10)$ & $5(-14$ to 22$)$ & 0.81 & $20(5)$ & $3(-15$ to 22$)$ & 0.94 \\
\hline Moderate & $37(25)$ & $33(12)$ & $4(-16$ to 23$)$ & 0.90 & $56(14)$ & $19(-4$ to 42$)$ & 0.15 \\
\hline Mild & $40(27)$ & $39(14)$ & $1(-19$ to 21$)$ & 0.90 & $24(6)$ & $16(-4$ to 36$)$ & 0.25 \\
\hline \multicolumn{8}{|l|}{ Parent's language } \\
\hline English & $98(57)$ & $89(25)$ & $9(-3$ to 21$)$ & 0.19 & $69(11)$ & 29 (6 to 52$)$ & 0.001 \\
\hline Other & $2(1)$ & $11(3)$ & & & $31(5)$ & & \\
\hline \multicolumn{8}{|c|}{ Visual impairment in the family } \\
\hline Yes & $13(7)$ & $46(13)$ & 33 (12 to 54$)$ & 0.002 & $23(5)$ & $9(-10$ to 28$)$ & 0.51 \\
\hline No & $87(48)$ & $54(15)$ & & & $76(18)$ & & \\
\hline \multicolumn{8}{|l|}{ Complexity of condition } \\
\hline Visual impairment alone & $60(41)$ & $50(18)$ & $10(-10$ to 30$)$ & 0.42 & $48(12)$ & $12(-10$ to 35$)$ & 0.41 \\
\hline Additional systemic problems & $40(27)$ & $50(18)$ & & & $52(13)$ & & \\
\hline \multicolumn{8}{|c|}{ Ethnicity* } \\
\hline White & $85(57)$ & $81(30)$ & $4(-11$ to 19$)$ & 0.80 & 71 (17) & $14(-6$ to 34$)$ & 0.22 \\
\hline Non-white & $15(10)$ & $19(7)$ & & & $29(5)$ & & \\
\hline \multicolumn{8}{|c|}{ Deprivation (population quintiles) } \\
\hline 1 st to 2 nd or 3 rd quintile & $69(29)$ & $67(15)$ & $2(-21$ to 25$)$ & 0.83 & $44(7)$ & $25(-3$ to 53$)$ & 0.15 \\
\hline 4 th or 5 th quintile & $31(13)$ & $33(7)$ & & & $56(9)$ & & \\
\hline \multicolumn{8}{|l|}{ Deprivation index } \\
\hline Mean & -.18 & -0.9 & $t=1.26$ & 0.21 & 1.58 & $t=-2.89$ & 0.005 \\
\hline SD & 2.75 & 2.79 & & & 3.31 & & \\
\hline \multicolumn{8}{|l|}{ Age of child } \\
\hline Mean & 2.11 & 2.53 & $t=-1.25$ & 0.21 & 1.83 & $t=.80$ & 0.43 \\
\hline SD & 1.67 & 1.56 & & & .87 & & \\
\hline
\end{tabular}

response rates in postal questionnaires, ${ }^{33}$ including personalised letters and questionnaires with reply paid envelopes sent by first class post from a university based group. Although the research team was independent of the clinical ophthalmology team from which the families were receiving care, it is possible that some parents did not participate because of concerns about this, ${ }^{22}$ despite the assurances given at the outset. A higher participation rate might have been achieved had non-responders been more actively pursued through other means; but this was considered unethical given the nature of our study and the incremental gain is likely to be have been small and costly. ${ }^{34}$

Participation might have been greater had validated versions of the MPOC in the languages of the main ethnic minority groups in the study been available, and we had been able to identify beforehand which parents needed them. The development of different language versions of self complete instruments is a complex task requiring careful backwards and forwards translation to ensure content and face validity. Indeed it is sometimes argued that it is more robust to develop new instruments specific to the sociocultural and linguistic contexts in which they are to be used. Such

\section{What is already known on this topic}

- The importance of engaging "users" of health care in research that informs the planning or provision of services is well established

- The case for this is particularly strong in relation to the parents of children with disability, whose role as advocates and mediators for their children is widely acknowledged

- There has been limited work on non-response bias in studies about disabled children and their families and about optimum ways of engaging them in research approaches were not possible with the resources available to us. Notably, from our experiences of prompting nonresponding parents from ethnic minorities by telephone, as well as from interviews conducted with those who did participate, we believe that language difficulties themselves were not the most important barrier to participation by these families. There is a pressing need for work to identify the obstacles to adequate representation of families from ethnic minorities in research on disability in childhood. It is likely that some may be similar to the barriers to participation by parents with lower incomes and/or educational attainment.

A major, insurmountable, barrier to recruitment in this study was the absence of correct contact details for one fifth of all eligible families. Every year in the United Kingdom almost $9 \%$ of children under 15 years move home, with families with children under 5 being particularly mobile. ${ }^{35}$ Such internal migration varies by ethnic group and socioeconomic status. ${ }^{35}$ It is likely that families of young children

\section{What this study adds}

- We have investigated the barriers to, and degree and nature of bias in, participation by parents of children with visual impairment in the United Kingdom in a study to elicit their health service experiences and needs

- Families from ethnic minorities and lower socioeconomic groups are less likely to be visible in such research and geographical mobility in families with young children is an important obstacle to participation

- It is important to investigate and address potential biases in the design and interpretation of future studies on children with disability to ensure equity in recommendations for policy and practice and in implementation of services 
with disability move home more often than others in industrialised countries, partly to improve access to appropriate services and schools. Thus, they would represent an important group in relation to coordination of services and their involvement in health services research would be particularly valuable. Maintenance of up to date contact information in hospital and community record systems, in particular daytime telephone numbers for parents, would benefit both clinical and research activities. In the absence of a clinical database from which the sampling frame for this study could be constructed or sociodemographic data extracted, a time consuming review of outpatient attendance lists and clinical notes was necessary.

Planning of responsive, appropriate, and comprehensive services for children with visual impairment requires the needs and experiences of all affected families to be carefully elicited. This necessitates engaging families in research in ways that they find acceptable and accessible and recognising that, despite the best approaches, it will be too difficult for some families to participate. ${ }^{22}$ We suggest that while it is clear that some families with disabled children will be more visible in health services research than others, neither the nature nor the extent of participation bias are predictable at the outset of a given study. Clinical databases (which include contact details, sociodemographic data, date of first assessment, and diagnosis) together with high quality hospital record systems are key foundations for robust research in this area. We advocate examination of both barriers to recruitment and participation biases as an ongoing process, to enable early detection of bias and alternative strategies, such as qualitative approaches, to be employed, to try to achieve adequate representation of all groups. The benefits would be more equitable policy and practice recommendations and implementation of services.

\section{ACKNOWLEDGEMENTS}

We are grateful to all parents who took part and Mr Kariofillis Zervoulis who contributed to data collection and analysis. We thank Professor David Taylor, Professor Catherine Peckham, Professor Alistair Fielder, and Dr Margaret Yerbury, who together comprised the study advisory group, for their helpful comments and discussions throughout its progress. This study was funded by a Health Services Project Grant from the Wellcome Trust.

\section{Authors' affiliations}

J S Rahi, Centre for Paediatric Epidemiology and Biostatistics and the Department of Ophthalmology, Institute of Child Health/Great Ormond Street Hospital, and the Department of Epidemiology, Institute of Ophthalmology, London, UK

I Manaras, Centre for Paediatric Epidemiology and Biostatistics, Institute of Child Health, London, UK

H Tuomainen, School of Health and Social Studies, University of Warwick, UK

G Lewando Hundt, Institute of Health, School of Health and Social

Studies, University of Warwick, UK

Commercial relationships: None.

\section{REFERENCES}

1 Bent N, Tennant A, Swift T, et al. Team approach versus ad hoc health services for young people with physical disabilities: retrospective cohort study. Lancet 2002;360:1280-6.

2 Read J. Disability, the Family and Society. Listening to mothers, 1 st ed. Milton Keynes: Open University Press, 2000.

3 Cleary PD. The increasing importance of patient surveys. BMJ 1999;319:720-1.
4 Milner J, Bungay C, Jellinek D, et al. Needs of disabled children and their families. Arch Dis Child 1996;75:399-404.

5 Crawford MJ, Rutter D, Manley, et al. Systematic review of involving patients in the planning and development of health care. BMJ 2002;325:1263-5.

6 Rahi JS, Dezateux C. Epidemiology of visual impairment. In: David TJ, ed. Recent advances in paediatrics 19. London: Churchill Livingstone, 2001:97-114.

7 King GA, Rosenbaum P, King SM. Evaluating family-centre service using a measure of parents' perceptions. Child Care Health Dev 1996;23:47-62.

8 King SM, Rosenbaum P, King GA. Parents' perceptions of caregiving: development and validation of a measure of processes. Dev Med Child Neurol 1996;38:757-72.

9 Larsson M. Organising habilitation services: team structures and family participation. Child Care Health Dev 2000;26:501-514.

10 Swaine BR, Pless IB, Friedmann DS, et al. Using the Measure of Processes of Care with parents of children hospitalised for head injury. Am J Phys Med Rehabii 1999;78:323-9

11 O'Neil ME, Palisano RJ, Westcott SL. Relationship of therapists' attitudes, children's motor ability, and parenting stress to mothers' perceptions of therapists' behaviors during early intervention. Phys Therapy 2001;81:1412-24.

12 Williams B. Patient satisfaction: a valid concept? Soc Sci Med 1994;38:509-16.

13 King G, Law M, King S, et al. Parents and service providers perceptions of the family-centredness of children's rehabilitation services. Phys Occup Ther Peadiatr 1998;18:21-39.

14 Larsen DL, Attkisson CC, Hargreaves WA, et al. Assessment of client/patient satisfaction: development of a general scale. Eval Program Plann 1979:2:197-207.

15 Krahn G, Eisert D, Fifield B. Obtaining parental perceptions of the quality of services for children with special needs. J Pediatr Psychol 1990;15:761-74.

16 Kirkwood BR. Essentials of medical statistics, 1 st ed. Oxford: Blackwell Scientific Publications, 1988.

17 Townsend P. Health and deprivation: inequalities and the north. London: Croom Helm, 1988.

18 Office for National Statistics. Birth Statistics 2000, Series FM1 no 29. London: Stationery Office, 2000.

19 Tennant A, Badley EM. Investigating non-response bias in a survey of disablement in the community: implications for sruvery methodology. $J$ Epidemiol Community Health 1991;45:247-50

20 Marchettti F, Bonati M, Marfisi RM, et al. Parental and primary care physicians' view on the management of chronic diseases: a study in Italy. Acta Paediatr 1995;84:1165-72.

21 Gowen JW, Schoen Christy D, Sparling J. Informational needs of parents of young children with special needs. J Early Intervention 1993;17:194-210.

22 Janus M, Goldberg S. Factors influencing family participation in a longitudinal study: comparison of pediatric and healthy samples. J Pediatric Psychol 1997;22:245-62

23 Saxena S, Eliahoo J, Majeed A. Socio-economic and ethnic differences in selfreported health status and us eof health services by children and young people in England: cross sectional study. BMJ 2002;325:520-3.

24 Cooper H, Smaje C, Arber S. Use of health services by children and young people according to ethnicity and social class: secondary analysis of a nation survey. BMJ 1998;317:1047-51.

25 Saxena S, Majeed A, Jones M. Socioeconomic differences in childhood consultation rates in general practice in England and Wales: prospective cohort study. BMJ 1999;318:642-6.

26 Lamers LM. Medical consumption of respondents and non-respondents to a mailed health survey. Eur J Public Health 1997;7:267-71.

27 Prendergast MJ. An investigation of non-response by comparison of dental health in 5 year old children according to parental response to a questionnaire. Community Dental Health 1993;10:225-34.

28 Sontag JC, Schacht R. An ethnic comparison of parent participation and information needs in early intervention. Exceptional Children 1994;60:422-33.

29 Pennefather PM, Tin W, Clarke MP, et al. Bias due to incomplete follow up in a cohort study. Br J Ophthalmol 1999;83:643-5.

30 Stallard P, Hutchison T. Development and satisfaction with individual programme planning in a disability service. Arch Dis Child 1995;73:43-7

31 Sloper P, Turner S. Service needs of families of children with severe physical disability. Child Care Health Dev 1992;18:259-82.

32 Peters TJ, Harvey IM, Bachmann $M O$, et al. Does requesting sensitive information on postal questionnaires have an impact on response rates? A randomised controlled trial in the south west of England. J Epidemiol Community Health 1998:52:130.

33 Edwards $\mathrm{P}$, Roberts I, Clarke $\mathrm{M}$, et al. Increasing response rates to postal questionnaires: systematic review. BMJ 2002;324:1183-5.

34 Morrison TC, Wahlgren DR, Hovell MF, et al. Tracking and follow-up of 16,915 adolescents: minimizing attrition bias. Control Clin Trials 1997; 18:383-96.

35 Office of Population Censuses and Surveys. Population review: migration to, from, and within the United Kingdom, Population Trends 83, 5-16. London: HMSO, 1996. 